\title{
Rearrangements of MYC gene facilitate risk stratification in diffuse large B-cell lymphoma patients treated with rituximab-CHOP
}

Alexandar Tzankov ${ }^{1,2}$, Zijun Y Xu-Monette ${ }^{1}$, Marc Gerhard ${ }^{2}$, Carlo Visco ${ }^{3}$, Stephan Dirnhofer ${ }^{2}$, Nora Gisin ${ }^{2}$, Karen Dybkaer ${ }^{4}$, Attilio Orazi ${ }^{5}$, Govind Bhagat ${ }^{6}$, Kristy L Richards ${ }^{7}$, Eric D Hsi ${ }^{8}$, William WL Choi ${ }^{9}$, J Han van Krieken ${ }^{10}$, Maurilio Ponzoni ${ }^{11}$, Andrés JM Ferreri ${ }^{11}$, Qing Ye ${ }^{12}$, Jane N Winter ${ }^{13}$, John P Farnen ${ }^{14}$, Miguel A Piris ${ }^{15}$, Michael B Møller ${ }^{16}$, M James You ${ }^{1}$, Timothy McDonnell ${ }^{1}$, $\mathrm{L}_{\text {Jeffrey Medeiros }}{ }^{1}$ and Ken H Young ${ }^{1}$

${ }^{1}$ Department of Hematopathology, The University of Texas MD Anderson Cancer Center, Houston, TX, USA; ${ }^{2}$ Department of Pathology, University Hospital, Basel, Switzerland; ${ }^{3}$ Department of Hematology, San Bortolo Hospital, Vicenza, Italy; ${ }^{4}$ Department of Pathology, Aalborg University Hospital, Aalborg, Denmark;

${ }^{5}$ Department of Pathology, Weill Medical College of Cornell University, New York, NY, USA; ${ }^{6}$ Department of Pathology, Columbia University Medical Center and New York Presbyterian Hospital, New York, NY, USA;

${ }^{7}$ Department of Hematology, University of North Carolina School of Medicine, Chapel Hill, NC, USA;

${ }^{8}$ Department of Clinical Pathology, Cleveland Clinic, Cleveland, OH, USA; ${ }^{9}$ Department of Pathology, University of Hong Kong Li Ka Shing Faculty of Medicine, Hong Kong, China; ${ }^{10}$ Department of Pathology, Radboud University Nijmegen Medical Centre, Nijmegen, The Netherlands; ${ }^{11}$ Unit of Lymphoid Malignancies, San Raffaele H Scientific Institute, Milan, Italy; ${ }^{12}$ Department of Pathology, Nanjing Drum Tower Hospital, Nanjing University Medical School, Nanjing, China; ${ }^{13}$ Department of Hematology, Feinberg School of Medicine, Northwestern University, Chicago, IL, USA; ${ }^{14}$ Department of Hematology, Gundersen Lutheran Health System, La Crosse, WI, USA; ${ }^{15}$ Department of Pathology, Hospital Universitario Marqués de Valdecilla/IFIMAV, Santander, Spain and ${ }^{16}$ Department of Pathology, Odense University Hospital, Odense, Denmark

In order to address the debatable prognostic role of $M Y C$ rearrangements in diffuse large B-cell lymphoma patients treated with rituximab, cyclophosphamide, hydroxydaunorubicin, vincristine, and prednisone, we evaluated $M Y C$ rearrangements by fluorescence in situ hybridization in 563 cases using break-apart probes and IGH/MYC dual-fusion probes. Concurrent BCL2 and BCL6 aberrations were also assessed. Data were correlated with clinicopathological variables and prognostic parameters. $M Y C$ rearrangements were observed in 39/432 evaluable cases $(9 \%)$, including 4 rearrangements detectable only with the dual-fusion probes, 15 detectable only with the break-apart probes and 20 detectable with both dual-fusion probes and break-apart probes. MYC rearrangements correlated with germinal center B-cell origin $(P=0.02)$, MYC protein expression $(P=0.032)$, and larger tumor mass size $(P=0.0003)$. Patients with $M Y C$ rearrangements were more likely to be treatment resistant $(P<0.0001)$. All types of $M Y C$ rearrangements were associated with poorer disease-specific survival, that is, 20/39 dead, median disease-specific survival 42 months, compared with 98/393 dead among the nonrearranged cases, median disease-specific survival not reached $(P=0.0002)$. Cases with $M Y C$ rearrangements that overexpressed MYC protein were at risk with respect to disease-specific survival independent of the International Prognostic Index $(P=0.046$ and $P<0.001$, respectively). Presence of concurrent $B C L 2$ aberrations but not of $B C L 6$ aberrations was prognostically additive. Radiotherapy seemed to diminish the prognostic effects of $M Y C$ rearrangements in diffuse large B-cell lymphoma patients since only 2/10 irradiated patients with MYC rearrangements died of/with disease, compared with 16/28 non-irradiated patients with MYC

Correspondence: Dr KH Young, MD, PhD, Department of Hematopathology, The University of Texas MD Anderson Cancer Center, 1515 Holcombe Boulevard, Houston, TX 77030-4009, USA and Professor Dr A Tzankov, MD, Institute of Pathology, University Hospital Basel, Schoenbeinstrasse 40, CH-4031 Basel, Switzerland.

E-mail: khyoung@mdanderson.org and atzankov@uhbs.ch

Received 23 July 2013; revised 1 October 2013; accepted 6 October 2013; published online 13 December 2013 


\begin{abstract}
rearrangements. We conclude that MYC rearrangements add prognostic information for individual risk estimation and such cases might represent a distinct, biologically determined disease subgroup.

Modern Pathology (2014) 27, 958-971; doi:10.1038/modpathol.2013.214; published online 13 December 2013
\end{abstract}

Keywords: diffuse large B-cell lymphoma; FISH; germinal center B-cell; MYC; prognosis; rearrangement; translocation

Diffuse large B-cell lymphoma accounts for 20-30\% of all lymphoid malignancies. This entity encompasses distinct morphological, molecular, and phenotypic variants and clinicopathological subgroups. ${ }^{1,2}$ However, most cases are classified as diffuse large B-cell lymphoma, not otherwise specified, because these cases do not meet the criteria of specific subtypes as proposed by the current World Health Organization classification system. ${ }^{1}$ Despite recent advances in the classification and molecular profiling of diffuse large B-cell lymphoma, its biological heterogeneity still hampers reliable prognostication and more specific treatment. Thus, identification of specific subgroups at risk for resistance to conventional therapy or relapse as well as subgroups that will benefit from specific or targeted therapies is of central interest. Diffuse large B-cell lymphoma can be classified by gene expression profiling into germinal center B-cell subtype, activated B-cell subtype, and unclassified subtype. ${ }^{3-5}$ Patient outcomes vary between these subtypes, and the germinal center B-cell subtype has a better outcome with the current standard rituximab, cyclophosphamide, hydroxydaunorubicin, vincristine, and prednisone (R-CHOP) immunochemotherapy. ${ }^{6}$ However, gene expression profiling does not capture all the biological parameters influencing diagnosis, clinical outcome, and response to therapy, nor is this modality feasible in daily practice.

The translocation $\mathrm{t}(8 ; 14)(\mathrm{q} 24 ; \mathrm{q} 23)$, juxtaposing the $C-M Y C$ (MYC) gene to the immunoglobulin heavy chain $(I G H)$ gene promoter, was the first translocation detected in lymphoid neoplasms. ${ }^{7}$ It can be identified in almost all cases of Burkitt lymphoma, particularly endemic cases, 30-50\% of unclassifiable B-cell lymphomas with features intermediate between diffuse large B-cell lymphoma and Burkitt lymphoma and in a smaller percentage of cases of diffuse large B-cell lymphoma, not otherwise specified. In unselected diffuse large B-cell lymphoma series, rearrangements of the MYC gene were discovered in approximately 5 to $10 \%$ of cases. $^{8-13}$ Of these, 20 to $30 \%$ may have an additional break in the BCL2 and/or BCL6 gene, ${ }^{14-16}$ fulfilling the criteria of so-called genetic double-hit lymphoma. The prognostic significance of $M Y C$ translocations in de novo diffuse large B-cell lymphomas, the gold standard for identifying such cases, their clinicopathological context, and gene expression profile are still debatable. ${ }^{17}$ More recently, the prognostic significance of $M Y C$ translocations has been challenged by the recognition of so-called phenotypic double-hit diffuse large B-cell lymphoma. ${ }^{14,18-21}$

To date, no study has been sufficiently statistically powered to resolve the current debatable issues regarding $M Y C$ aberrations in diffuse large B-cell lymphoma and the significance of genetic MYC single-hits vs double-hits in the context of phenotypic double-hits. The goal of this study was to address the above issues in a large number of patients with de novo diffuse large B-cell lymphoma, who were treated with R-CHOP, and stratified according to cell of origin.

\section{Materials and methods}

\section{Patients}

We studied 563 untreated de novo diffuse large B-cell lymphoma patients, diagnosed between January 2002 and October 2009. Formalin-fixed and paraffinembedded lymphoma samples were used to generate tissue microarrays as part of the International Diffuse Large B-Cell Lymphoma Rituximab-CHOP Consortium Program Study. All cases were reviewed by a group of hematopathologists (MAP, MBM, AT, and KHY) based on the current World Health Organization criteria. ${ }^{1}$ Presence of a starry sky pattern, mitotic counts, and lymphoma cytology were assessed by two investigators (AT and KHY). Patients with diffuse large B-cell lymphomas transforming from low-grade lymphoma, those with primary mediastinal large B-cell lymphomas, primary cutaneous, and primary central nervous system diffuse large B-cell lymphomas, as well as individuals infected by the human immunodeficiency virus were excluded from analysis. Data collection protocols were approved by each of the participating centers' Institutional Review Boards and the study was approved by the Institutional Review Board at the University of Texas MD Anderson Cancer Center in Houston, TX, USA. Disease responses to treatment were defined according to the revised International Working Group criteria. $^{22}$ Disease relapses were defined as disease recurrences after remission. Follow-up data were provided by the participating centers and are updated yearly.

\section{Treatment}

Treatment consisted of R-CHOP $(n=476,85 \%)$, generally six cycles of R-CHOP-21 with or without 
two additional cycles of rituximab, or an R-CHOPlike regimen $(n=87,15 \%$; of these, 61 patients were given the R-CEOP scheme, whereas in the remaining 26 patients hydroxydaunorubicin was either dose adjusted or substituted). Radiotherapy followed chemotherapy in 147 (26\%) patients, and was administered according to protocols adopted by the referring physician at each center; half of the patients treated with $<6 \mathrm{R}-\mathrm{CHOP}$ cycles compared with only one-fifth of the patients treated with $\geq 6$ R-CHOP $(P=0.0003)$ were irradiated.

\section{Fluorescence In Situ Hybridization for MYC Gene Rearrangements}

Fluorescence in situ hybridization (FISH) was performed with a locus-specific identifier IGH/MYC/ CEP 8 tri-color, dual-fusion probe (05J75-001 from Abbott/Vysis, Downers Grove, IL, USA). Owing to the inability of the former to identify alternative (non-IGH) MYC rearrangement partners, the locusspecific identifier $M Y C$ dual-color, break-apart probe (05J91-001 from Abbott/Vysis) was applied as well. Both probes were used according to the manufacturer's protocols. In addition, BCL2 and BCL6 gene rearrangements were studied with respective break-apart probes (07J75-001 and 01N23020 from Abbott/Vysis, respectively). Cases on the tissue microarray were considered for evaluation if at least 200 tumor cell nuclei per core displayed positive FISH signals. Abnormal FISH signals were recorded as percentage of total tumor cells showing an abnormality. The cutoff score to consider a case rearranged was the mean +3 s.d. of nuclei with fused or split signals in reference cases (ie, $>6.5 \%$ for $I G H / M Y C$ fusions, $>4 \%$ for $M Y C$ breaks, $>3 \%$ for $B C L 2$ breaks, and $>1.5 \%$ for BCL6 breaks). ${ }^{12,23,24}$ High-level 8q24 amplification was defined as the presence of either $\geq 6$ gene signals or tight clusters of at least five gene signals per cell. Polysomies/ trisomies and low-level amplifications (referred together as 'gains') were defined as cases in which the number of tumor cell nuclei with three or more signals exceeded the mean +3 s.d. of trisomic/ polysomic nuclei in the reference cases (ie, >5\%). Five tonsils were used as references. To assess reproducibility, comparison between the results of two observers (MG and AT) were performed in a blinded manner in 100 cases; the agreement was perfect for breaks $(\kappa=1)$ and excellent for gains $(\kappa=0.89)$.

\section{Immunohistochemical Analysis for MYC and Ki-67 and Cutoff Determination}

All patient samples were evaluated for MYC protein expression, using the monoclonal anti-(c)MYC antibody, clone Y69 (Epitomics, Burlingame, CA, USA), at 1:100 dilution as described elsewhere. ${ }^{18}$ The percentage of stained tumor cells was counted and recorded in 5\% increments, and $>95 \%$ staining for MYC protein was considered positive with respect to $M Y C$ rearrangements. This value was established from the analysis of the area under the receiver operating characteristic curves ${ }^{25}$ and had the maximum specificity (36\%) and sensitivity (91\%) to predict $M Y C$ breaks in our patient samples (area $=0.599,95 \%$ confidence interval 0.484-0.715, $P=0.063$ ). Considering prognosis, the receiver operating characteristic curve indicated that $75 \%$ was the most relevant MYC protein expression cutoff score. Both $95 \%$ and $75 \%$ and the score proposed by Green et $a l^{18}$ (median expression) were used for survival analyses. The Ki-67 labeling index was assessed by counting, in 5\% increments, MIB-1 signals utilizing the respective monoclonal antibody at 1:100 dilution (DAKO, Carpinteria, CA, USA). Expression data for $\mathrm{Bcl} 2$ on these cases were available as a result of earlier studies ${ }^{19,26}$ and were utilized for statistical analysis.

\section{Gene Expression Profiling}

Total RNA extracted from each formalin-fixed, paraffin-embedded tissue sample was subjected to gene expression profiling using Affymetrix GeneChip Human Genome HG-U133 Plus 2.0 to classify 476 diffuse large B-cell lymphoma cases into germinal center B-cell subtypes or activated B-cell subtypes as previously described, ${ }^{27}$ and to determine gene expression signatures according to $M Y C$ rearrangements.

\section{Cell of Origin Classification}

Cell of origin classification was attempted by both gene expression profiling and immunohistochemistry, with gene expression profiling considered as the gold standard. Briefly, gene expression profiling was performed in 476 cases, 433 of which were classifiable. Immunohistochemistry was performed in all 563 cases, 553 of which were evaluable. The 43 cases unclassifiable by GEP and the 87 cases, in which gene expression profiling was not performed, were further classified by immunohistochemistry according to the Visco/ Young algorithm. ${ }^{27}$

\section{Statistical Analyses}

All statistical analyses were performed using the Statistical Package of Social Sciences (IBM SPSS version 19.0, Chicago, IL, USA) for Windows and reported applying the REMARK guidelines. ${ }^{28}$ The interobserver agreement for FISH was assessed using the $\kappa$ statistic; a $\kappa$ value of $>0.75$ implying excellent agreement. The Pearson $\chi^{2}$ statistic, the Spearman rank correlation, and the Fisher's exact test were used where appropriate to analyze 
relationships between biomarkers and clinical and laboratory parameters. The Mann-Whitney $U$ and Kruskal-Wallis tests were applied where appropriate to identify quantitative differences between groups. Overall survival was measured from the time of diagnosis to last follow-up or to death from any cause. Disease-specific survival was measured from the time of diagnosis to last follow-up or to death of/with disease. Progression-free survival was measured from the time of diagnosis to the time of progression, relapse, or death of/with disease. The probabilities of survival were determined using the Kaplan-Meier method, and differences were compared by the log-rank test. All variables of prognostic significance in the univariable model (log-rank test) were evaluated using the Cox proportional hazards model for multivariate analysis. A $P<0.05$ was considered statistically significant.

\section{Results}

\section{Patient Characteristics}

Our cohort consisted of 326 male patients ( $58 \%$, mean age $60 \pm 15$ years) and 237 female patients $(42 \%$, mean age $63 \pm 14$ years). There were 393 primary nodal lymphomas and 170 were extranodal; the most common extranodal locations encompassed the head and neck region $(n=44)$, gastro-intestinal tract $(n=36)$, testicles $(n=23)$, bones $(n=11)$, and female genital tract $(n=10)$. The following clinical findings were unavailable in some of the patients: stage $(n=16)$, B-symptoms $(n=66)$, serum lactate dehydrogenase $(n=54)$, International Prognostic Index $(n=61)$, and maximum tumor diameter $(n=143)$. For the rest of the group, the clinical findings were: stage I (29\%), II (21\%), III (22\%), and IV (28\%); B-symptoms (34\%), elevated lactate dehydrogenase (67\%); International Prognostic Index of 0-1 (low; $42 \%$ ), 2 (low-intermediate; $24 \%$ ), 3 (high-intermediate; $20 \%$ ), 4-5 (high; 15\%), and mean largest tumor mass of $5.7 \pm 3.5 \mathrm{~cm}$ (range $1-18 ; 16 \%>10 \mathrm{~cm}$, ie, bulky disease). ${ }^{29}$

After therapy, complete remission was achieved in $424(75 \%)$ patients, partial remission in $75(13 \%)$, stable disease in $25(4 \%)$, and $39(7 \%)$ had progressive disease. Within the mean observation period of 43.4 months (range 1-140, median 40), there were 184 recurrences and $212(38 \%)$ patients died, $147(26 \%)$ of whom died of/with disease. Mean overall survival was 81 months (95\% confidence interval 72-90), median was reached after 85 months (95\% confidence interval 75-97), mean disease-specific survival was 118 months (95\% confidence interval 112-124), median was not reached, mean progression-free survival was 73 months (95\% confidence interval 67-80) and median was reached after 76 months (95\% confidence interval 66-86).

\section{Histopathological Features, Immunophenotype, and Cell of Origin}

There were 20 cases (4\%) with immunoblastic morphology. Mitotic counts $>20 / \mathrm{mm}^{2}$ were observed in $116(27 \%)$ neoplasms and starry sky pattern in 31 $(7.3 \%)$. The mean proliferation rate was $71 \%$ (median 70\%, range 30-95\%). Mean MYC protein expression was $52 \%$ of the tumor cells (median $50 \%$, range $0-100 \%$ ). Considering cell of origin, 261 of $553(47 \%)$ cases were of the activated B-cell subtype according to immunohistochemistry ${ }^{27}$ and 207 of $433(48 \%)$ according to gene expression profiling, whereas $292(53 \%)$ and $226(52 \%)$ were of the germinal center B-cell subtype, respectively; 10 cases could not be classified by either method.

\section{Fluorescence In Situ Hybridization}

A total of $376(67 \%)$ cases were evaluable for BCL6 by FISH, $440(78 \%)$ for BCL2, $428(76 \%)$ for IGH/MYC fusions, and $432(77 \%)$ for $M Y C$ breaks. Technical problems such as hybridization failures and non-specific or weak fluorescence were responsible for $75 \%$ of the non-analyzable cases, whereas the others were because of too few cells or empty or non-informative spots on the tissue microarray. The most commonly rearranged gene in our cohort was $B C L 6$, with breaks in 121 of 376 cases (32\%). The mean proportion of cells with BCL6 rearrangements in positive cases was $44 \pm 29 \%$ (median $50 \%$ ). Six additional cases $(1.6 \%)$ showed high-level amplifications and $89(24 \%)$ showed other types of gene gains. BCL2 was rearranged in 80 of $440(18 \%)$ of cases. The mean proportion of cells with BCL2 rearrangements in positive cases was $67 \pm 22 \%$ (median 70\%). Four further cases (1\%) showed high-level amplifications and $54(12 \%)$ showed other types of gene gains.

Structural aberrations of $M Y C$ were detected in 39 cases $(9 \%)$, including $20(51 \%)$ rearrangements detectable with both probes and thus corresponding to the classical $\mathrm{t}(8 ; 14), 15(38 \%)$ rearrangements detectable only with the break-apart probe (Figure 1a) and thus likely corresponding to non$I G H$ rearrangement partners of $M Y C$ including the light chain loci, ZCCHC7, ZBTB5, BCL11A, or BCL6; the latter might apply to three cases of our series in which both $M Y C$ and BCL6 breaks were detected but there were no $I G H / M Y C$ fusions. ${ }^{30-32}$ In four cases (11\%), MYC rearrangements were detectable only with the dual-fusion probe (Figure 1b) and thus corresponded to $\mathrm{t}(8 ; 14)$ with $M Y C$ breaks >100-bp $5^{\prime}$ to the first gene exon, which are typical for endemic Burkitt lymphomas and are not detectable by the applied break-apart probe. ${ }^{33,34}$ Three cases with $M Y C$ breaks showed telomeric deletions and one telomeric amplification or double minutes. The mean proportion of cells with $M Y C$ breaks in positive cases was $47 \pm 26 \%$ (median $50 \%$ ), whereas the mean proportion of cells with IGH/MYC fusions 

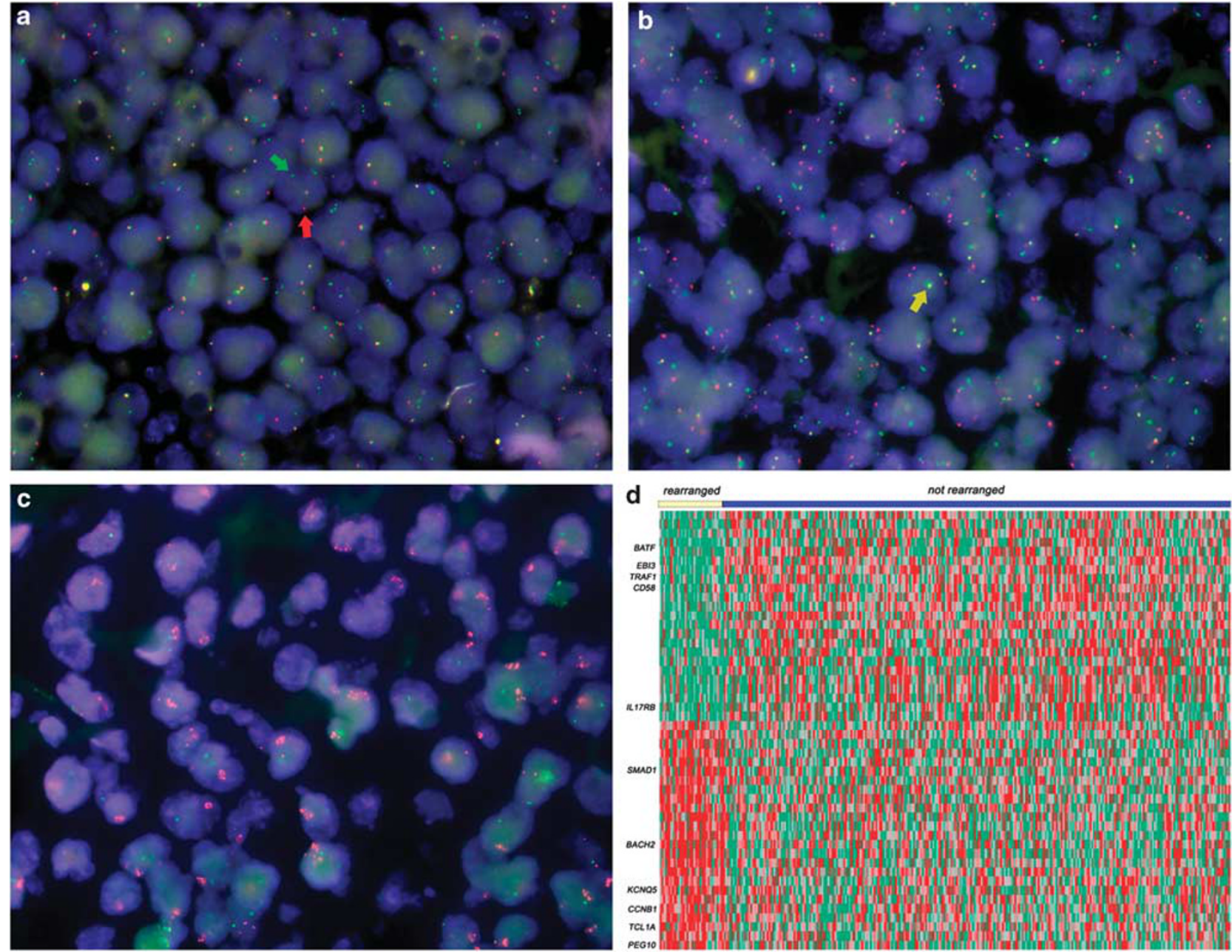

Figure 1 Fluorescence in situ hybridization analysis of $M Y C$ in diffuse large B-cell lymphomas. (a) MYC rearrangements detected with the dual-color, break-apart probe. Note split green (telomeric, green arrow) and red signals (centromeric, red arrow) corresponding to MYC rearrangement. This case was negative with the MYC/IGH dual-fusion probe, thus a non-IGH rearrangement partner can be assumed. (b) MYC rearrangements detected with the tri-color, dual-fusion probe. Note fused yellow (arrow) signals corresponding to $M Y C$ (red)/IGH (green) fusions in t(8;14). The free red and green signals correspond to the non-rearranged $M Y C$ and IGH alleles. (c) $M Y C$ amplification detected with the tri-color, dual-fusion probe. Note that the red signals $(M Y C)$ are highly increased but there are only one to two green signals (IGH). (d) Gene expression profile of 281 patients (30 with MYC rearrangements) with both available GEP and MYC FISH data, stratified according to the presence or absence of $M Y C$ rearrangements.

in positive cases was $39 \pm 27 \%$ (median $30 \%$ ), explained by the fact that the dual-fusion probe is more prone to cut-artifacts. There were 3 cases $(0.7 \%)$ with high-level amplifications of $M Y C$ (Figure 1c) and 55 cases (13\%) with other types of gene gains. Cases with high-level amplifications of $M Y C$ were not associated with any specific clinicopathological parameters or outcome and were not considered further. Cumulatively, 8 of 322 (2\%) cases evaluable for all FISH probes showed gains of $B C L 2, B C L 6, M Y C$, and $I G H$, suggesting polyploidy, but they were not associated with any specific clinicopathological parameters or outcome and were not considered further. There were eight BCL2/MYC and four $B C L 6 / M Y C$ genetic double-hit cases as well as two $B C L 2 / B C L 6 / M Y C$ triple-hit cases. In four of the $B C L 2 / M Y C$ and in one of the BCL6/MYC genetic double-hit cases and in both BCL2/BCL6/MYC triple-hit cases, $M Y C$ had a non-IGH rearrangement partner. Altogether, there were 14 genetic double-hit and triple-hit cases out of $39 M Y C$ rearranged diffuse large B-cell lymphomas (36\%), which is within the range of published series. ${ }^{14-16,20}$ BCL6/MYC genetic double-hit cases were not associated with any specific clinicopathological parameters or outcome and were not considered further.

\section{Clinicopathological Context of Cases with MYC Aberrations}

All significant differences in clinicopathological parameters between $M Y C$ rearranged and nonrearranged cases are shown in Table 1, whereas those of MYC protein overexpressing cases are shown in Table 2. Importantly, MYC rearranged 
Table 1 Clinicopathological characteristics of diffuse large B-cell lymphoma patients stratified by MYC rearrangement status

\begin{tabular}{|c|c|c|c|}
\hline Variable $^{\mathrm{a}}$ & MYC non-rearranged & MYC rearranged & $\mathrm{P}$-value \\
\hline Age, years & $62 \pm 15$ & $60 \pm 16$ & NS \\
\hline Gender (male: female) & 1.35: 1 (226: 167) & 1.29: $1(22: 17)$ & NS \\
\hline B-symptoms & $127 / 356(36 \%)$ & 12/38 (32\%) & NS \\
\hline Mass size, $\mathrm{cm}$ & $5.4 \pm 3.3$ & $7.8 \pm 4.7$ & 0.0003 \\
\hline Bulky tumor $(>10 \mathrm{~cm})$ & $42 / 312(13 \%)$ & $10 / 29(34 \%)$ & 0.006 \\
\hline Nodal: extranodal primary & 2.25: 1 (272: 121) & 2.25: $1(27: 12)$ & NS \\
\hline Stage (I/II/III/IV) & $108 / 75 / 90 / 110$ & $7 / 8 / 5 / 17$ & NS \\
\hline Lactate dehydrogenase (U/1) & $399 \pm 438$ & $393 \pm 403$ & NS \\
\hline International Prognostic Index $(0-1 / 2 / 3 / 4-5)$ & $147 / 77 / 68 / 54$ & $10 / 10 / 10 / 6$ & NS \\
\hline R-CHOP-like regimens & $62 / 393(16 \%)$ & $3 / 39(8 \%)$ & NS \\
\hline Radiotherapy & $103 / 392(26 \%)$ & $10 / 39(26 \%)$ & NS \\
\hline Complete remission & $306 / 393(78 \%)$ & $22 / 39(56 \%)$ & 0.00002 \\
\hline Relapses & $136 / 393(35 \%)$ & 9/39 (23\%) & NS \\
\hline Mitotic count $>20 / \mathrm{mm}^{2}$ & $82 / 306(27 \%)$ & $10 / 34(29 \%)$ & NS \\
\hline Starry sky pattern & $22 / 306(7 \%)$ & $1 / 34(3 \%)$ & NS \\
\hline MYC protein, mean \% & $52 \pm 27$ & $63 \pm 33$ & 0.032 \\
\hline Ki-67, mean \% & $71 \pm 17$ & $73 \pm 19$ & NS \\
\hline Bcl2, mean \% & $51 \pm 36$ & $58 \pm 41$ & NS \\
\hline Germinal center B-cell like & $192 / 390(49 \%)$ & $27 / 39(69 \%)$ & 0.02 \\
\hline Phenotypic double-hits ${ }^{19}$ & $105 / 393(27 \%)$ & $16 / 38(42 \%)$ & 0.037 \\
\hline$B C L 2$ breaks & $63 / 355(18 \%)$ & $10 / 34(29 \%)$ & NS \\
\hline$B C L 6$ breaks & $105 / 301(35 \%)$ & $7 / 33(21 \%)$ & NS \\
\hline
\end{tabular}

Abbreviation: NS, not significant.

${ }^{\mathrm{a} D a t a}$ represent absolute numbers, ratios, or means.

Table 2 Clinicopathological characteristics of diffuse large B-cell lymphoma patients stratified by MYC protein expression status

\begin{tabular}{|c|c|c|c|}
\hline Variable $^{\mathrm{a}}$ & $M Y C<95 \%{ }^{\mathrm{b}}$ & $M Y C>95 \%$ & $\mathrm{P}$-value \\
\hline Age, years & $61 \pm 14$ & $65 \pm 14$ & NS \\
\hline Gender (male: female) & 1.38: 1 (200: 144) & $1: 1(21: 20)$ & NS \\
\hline B-symptoms & $102 / 292(35 \%)$ & $11 / 39(28 \%)$ & NS \\
\hline Mass size, $\mathrm{cm}$ & $5.9 \pm 3.7$ & $7.1 \pm 4.1$ & NS \\
\hline Bulky tumor $(>10 \mathrm{~cm})$ & $43 / 243(18 \%)$ & $9 / 33(27 \%)$ & NS \\
\hline Nodal: extranodal primary & 2.34: 1 (241: 103) & 1.92: $1(27: 14)$ & NS \\
\hline Stage (I/II/III/IV) & $81 / 71 / 80 / 100$ & 15/6/9/11 & NS \\
\hline Lactate dehydrogenase (U/l) & $410 \pm 467$ & $421 \pm 467$ & NS \\
\hline International Prognostic Index $(0-1 / 2 / 3 / 4-5)$ & $120 / 73 / 64 / 45$ & $15 / 13 / 9 / 4$ & NS \\
\hline R-CHOP-like regimens & $58 / 344(17 \%)$ & $5 / 41(12 \%)$ & NS \\
\hline Radiotherapy & $83 / 343(24 \%)$ & $10 / 41(24 \%)$ & NS \\
\hline Complete remission & $253 / 344(74 \%)$ & $26 / 41(63 \%)$ & NS \\
\hline Relapses & $116 / 344(34 \%)$ & $15 / 41(37 \%)$ & NS \\
\hline Mitotic count $>20 / \mathrm{mm}^{2}$ & $81 / 303(27 \%)$ & $19 / 37(51 \%)$ & 0.004 \\
\hline Starry sky pattern & $18 / 285(6 \%)$ & $6 / 37(16 \%)$ & 0.034 \\
\hline MYC (protein), mean \% & $47 \pm 24$ & $100 \pm 1$ & $<0.0001$ \\
\hline Ki-67, mean \% & $70 \pm 18$ & $76 \pm 18$ & 0.037 \\
\hline Bcl2, mean \% & $52 \pm 37$ & $65 \pm 35$ & 0.041 \\
\hline Germinal center B-cell like & $176 / 340(52 \%)$ & $17 / 41(42 \%)$ & NS \\
\hline Phenotypic double-hits ${ }^{19}$ & $112 / 344(33 \%)$ & $27 / 41(66 \%)$ & 0.00051 \\
\hline$B C L 2$ breaks & $55 / 278(20 \%)$ & $8 / 35(23 \%)$ & NS \\
\hline$B C L 6$ breaks & $78 / 265(29 \%)$ & $9 / 31(29 \%)$ & NS \\
\hline$M Y C$ rearrangements & $21 / 265(8 \%)$ & $12 / 37(32 \%)$ & $<0.0001$ \\
\hline
\end{tabular}

Abbreviation: NS, not significant.

${ }^{\mathrm{a}}$ Data represent absolute numbers, ratios, or means.

${ }^{\mathrm{b}}$ Application of a cutoff score of $75 \%$ (data not shown) rendered different absolute numbers, but similar ratios and means as well as similar statistical significance values.

cases expressed CD10 (57 $\pm 45 \% \quad$ CD10-positive tumor cells) more abundantly than non-rearranged cases $(32 \pm 40 \%, P=0.003)$. Two of $35 M Y C$ rearranged cases $(6 \%)$ displayed immunoblastic morphology. Twelve of $33 M Y C$ rearranged cases (36\%) that had both MYC FISH and MYC protein expression data available expressed MYC protein in > $95 \%$ of tumor cells, whereas only 24 of 269 (9\%) nonrearranged cases expressed MYC protein in $>95 \%$ $(P=0.00008)$; the positive predictive value of MYC 
protein overexpression to detect $M Y C$ rearranged cases was $60 \%$. Importantly, there was one $M Y C$ rearranged case, which did not show detectable MYC protein expression, despite internal positive controls stained as expected, and additional five expressed MYC protein in $<40 \%$ of tumor cells. $M Y C$ rearranged cases were overrepresented among the phenotypic double-hit diffuse large B-cell lymphomas as defined in our recent study: ${ }^{19}$ there were $16 M Y C$ rearranged cases of 121 (13\%) phenotypic double-hits compared with $22 M Y C$ rearranged cases of $310(7 \%)$ phenotypic non-double-hit cases $(P=0.037)$. Of the genetic multiple-hit lymphomas, both triple-hit lymphomas, 6 of 8 BCL2/MYC double-hit cases (75\%) and 2 of 4 BCL6/MYC double-hit cases (50\%) were of germinal center B-cell origin, all had elevated lactate dehydrogenase levels, half ( 7 of 14) had bulky tumors, 6 of $14(43 \%)$ failed to achieve complete remission and 9 of $14(64 \%)$ experienced recurrence.

\section{Clinical Outcomes of Diffuse Large B-Cell Lymphomas with MYC Gene Aberrations}

The specific impact of $M Y C$ aberrations on prognosis of diffuse large B-cell lymphoma patients is shown in Table 3 and Figures 2a and b. Importantly, all patients with $M Y C$ hits who died did so because of/with disease, and thus in such instances overall survival and disease-specific survival were identical. Other factors associated with inferior overall survival, disease-specific survival, and progressionfree survival in our cohort were higher International Prognostic Index scores $(P=1.3 \mathrm{e} 11,4.7 \mathrm{e} 13$, and 8.7e12, respectively), presence of bulky disease
$(P=0.002,0.001$, and 0.006 , respectively), presence of B-symptoms $(P=0.001,0.0002$, and 0.0002, respectively), activated B-cell origin $(P=0.003$, 0.005 , and 0.001 , respectively), phenotypic doublehits, that is, cases co-expressing MYC (cutoff $\geq 40 \%$ ) and Bcl2 (cutoff $\geq 70 \%$ ) at the protein level as defined in our former study ${ }^{19}(P=0.05,0.006$, and 0.007 , respectively), expression of $\mathrm{Bcl} 2$ in $\geq 70 \%$ of the tumor cells $(P=0.003,0.002$, and 0.001 , respectively) and application of R-CHOP-like regimens rather than R-CHOP $(P=0.007,0.04$, and 0.028 , respectively). Expression of MYC protein in $>75 \%$ (receiver operating characteristic curve-suggested prognostic cutoff score) or $>95 \%$ (most relevant predictive score for $M Y C$ rearrangements) of tumor cells was associated with adverse overall survival $(P=0.1$ and 0.032 , respectively) and disease-specific survival $(P=0.036$ and 0.025 , respectively); when other cutoff scores $(50 \%, 40 \%)$ were applied the survival differences between MYC protein 'positive' and 'negative' cases lost statistical significance. When cases that did not display $M Y C$ rearrangements were analyzed separately, MYC protein expression did not add any prognostic information. Yet, an integrative approach considering both MYC FISH and MYC protein expression data, applying either the prognostically relevant cutoff score of $75 \%$ ( $P$-values for overall survival, diseasespecific survival, and progression-free survival, 0.01 , $1.5 \mathrm{e} 6$, and 0.002 , respectively) or the median $(50 \%$; $P=0.03$, 3.3e5, and 0.011 , respectively), improved the prognostic performance of $M Y C$ (Figure 2c). Radiotherapy improved disease-specific survival $(P=0.03)$, and this improvement was more profound in patients with stage I disease $(P=0.006)$. When genetic single-hit and double-hit cases were analyzed

Table 3 Prognostic importance of $M Y C$ rearrangements in diffuse large B-cell lymphomas

\begin{tabular}{|c|c|c|c|c|c|c|}
\hline \multirow{2}{*}{ MYC status } & \multicolumn{2}{|c|}{ Overall survival } & \multicolumn{2}{|c|}{ Disease-specific survival } & \multicolumn{2}{|c|}{ Progression-free survival } \\
\hline & $\begin{array}{c}\text { Dead/ } \\
\text { all patients } \\
(\%)\end{array}$ & $\begin{array}{c}\text { Mean (95\% } \\
\text { confidence interval), } \\
\text { median, } \\
\text { months }\end{array}$ & $\begin{array}{c}\text { Dead/ } \\
\text { all patients (\%) }\end{array}$ & $\begin{array}{c}\text { Mean } \\
\text { (95\% confidence } \\
\text { interval), median, } \\
\text { months }\end{array}$ & $\begin{array}{c}\text { Progressed/ } \\
\text { all patients } \\
(\%)\end{array}$ & $\begin{array}{c}\text { Mean (95\% } \\
\text { confidence } \\
\text { interval), } \\
\text { median, months }\end{array}$ \\
\hline Non-rearranged & $145 / 393(37)$ & $79(72-86), 86$ & $98 / 393(25)$ & $99(93-104),-$ & $167 / 393(42)$ & $71(65-80), 75$ \\
\hline Rearranged & 20/39 (51) & $58(42-74), 42$ & 20/39 (51) & $58(42-74), 42$ & 22/39 (56) & 54 (39-69), 42 \\
\hline$P$-value & \multicolumn{2}{|c|}{0.038} & \multicolumn{2}{|c|}{0.0002} & \multicolumn{2}{|c|}{0.049} \\
\hline $\mathrm{t}(8 ; 14)$ & $9 / 20(45)$ & 57 (39-75), 42 & $9 / 20(45)$ & 57 (39-75), 42 & $10 / 20(50)$ & $54(36-71), 42$ \\
\hline $\mathrm{t}(8 ; 14) 5$ & $2 / 4(50)$ & 59 (12-107), 55 & $2 / 4(50)$ & 59 (12-107), 55 & $2 / 4(50 \%)$ & 59 (12-107), 55 \\
\hline & $9 / 15(60)$ & $42(25-59), 38$ & $9 / 15(60)$ & 42 (25-59), 38 & 10/15 (67) & $40(24-56), 38$ \\
\hline $\begin{array}{l}\text { non-IGH rearrangements } \\
P \text {-value }\end{array}$ & \multicolumn{2}{|r|}{0.006} & \multicolumn{2}{|c|}{0.00005} & \multicolumn{2}{|r|}{0.002} \\
\hline $\begin{array}{l}B C L 2 / M Y C \text { double-hits } \\
P \text {-value }\end{array}$ & \multicolumn{2}{|c|}{0.145} & \multicolumn{2}{|c|}{0.02} & \multicolumn{2}{|c|}{0.034} \\
\hline $\begin{array}{l}M Y C \text { rearranged }{ }^{\mathrm{a}} \text {, low } \mathrm{MYC} \\
\text { protein expression }\end{array}$ & $7 / 20(35)$ & $73(50.95), 77$ & $7 / 20(35)$ & $73(50.95), 77$ & $9 / 20(45)$ & $64(44-84), 62$ \\
\hline $\begin{array}{l}M Y C \text { rearranged, high } \mathrm{MYC} \\
\text { protein expression }\end{array}$ & $10 / 13(77)$ & 29 (10-48), 10 & $10 / 13(77)$ & 29 (10-48), 10 & $10 / 13(77)$ & 29 (10-48), 10 \\
\hline$P$-value & \multicolumn{2}{|r|}{0.007} & \multicolumn{2}{|c|}{0.007} & \multicolumn{2}{|r|}{0.022} \\
\hline
\end{tabular}

aAs MYC protein expression in non-rearranged instances was not of prognostic value detailed survival data are not shown. 

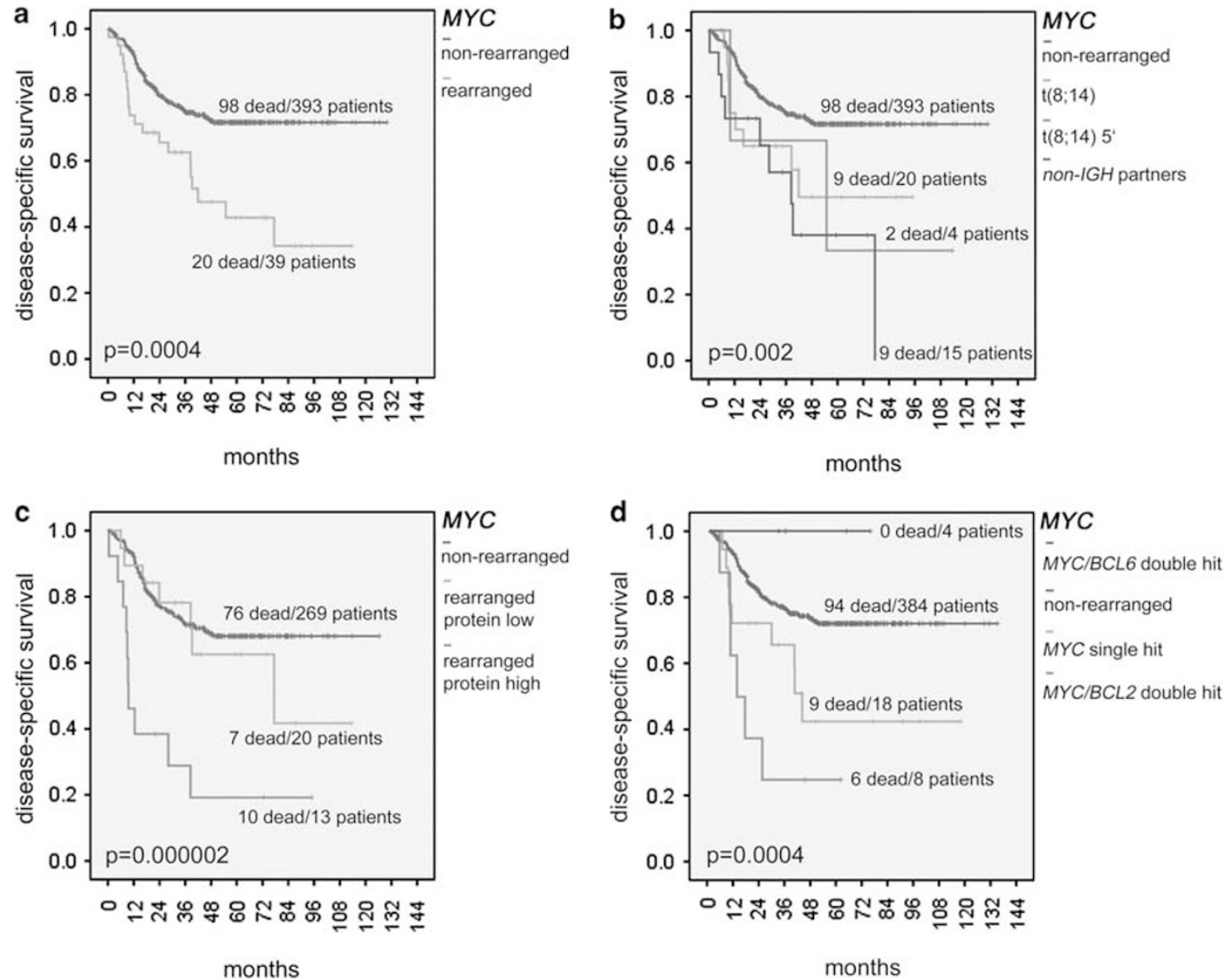

Figure 2 Kaplan-Meier survival curves comparing $M Y C$ rearranged and non-rearranged cases. (a) Survival estimates according to presence or absence of structural MYC hits. (b) Survival estimates according to exact type of structural MYC hits. (c) Survival estimates according to the presence or absence of overexpression of MYC protein ( $>75 \%$ of tumor cells) in addition to MYC hits. (d) Survival estimates according to presence or absence of structural BCL2 and/or BCL6 hits in addition to MYC hits.

separately, the presence of ' $M Y C$ only' hits retained their prognostic relevance (Figure 2d). Even within the sub-cohort of phenotypic double-hit diffuse large B-cell lymphoma patients, presence of $M Y C$ rearrangements was associated with more unfavorable outcomes $(P$-values for overall survival, disease-specific survival, and progression-free survival, 0.012, 0.003, and 0.018, respectively; Figure 3a).

When analyzed in subgroups, defined by bulky disease, B-symptoms and International Prognostic Index, the presence of $M Y C$ rearrangement retained its negative prognostic impact for overall survival, disease-specific survival, and progression-free survival in all subgroups except patients with a high-intermediate International Prognostic Index. MYC rearrangement retained its prognostic significance for disease-specific survival, but not for overall survival and progression-free survival in patients whose diffuse large B-cell lymphomas expressed Bcl 2 in $\geq 70 \%$ of the tumor cells. MYC rearrangement predicted poorer overall survival, disease-specific survival, and progression-free survival, in cases expressing $\mathrm{Bcl} 2$ in $<70 \%$ of the tumor cells. Presence of MYC rearrangement also retained its effect on disease-specific survival in patients treated with R-CHOP and in those treated with R-CHOP-like regimens. When analyzed according to cell of origin, the prognostic significance of $M Y C$ rearrangements applied exclusively to germinal center B-cell cases (Figure 3b). When disease stages I-II patients were stratified according to whether or not they were given adjuvant radiotherapy, the negative prognostic role of $M Y C$ rearrangements was observed in non-irradiated patients, whereas addition of radiotherapy seemed to possibly equalize the prognostic impact of $M Y C$ rearrangements by increasing the mean survival from 49 months (non-irradiated patients with $M Y C$ rearrangements and limited stage diffuse large B-cell lymphoma, 95\% confidence interval 27-72, median 39; 5 dead of 9 patients, ie, $55 \%$ ) to 61 months (irradiated patients with $M Y C$ rearrangements and limited stage diffuse large B-cell lymphoma, 95\% confidence interval 38-83, median not reached; 1 dead of 6 patients, ie, 17\%; Figures 3c and d and Table 4); a direct comparison of the six $M Y C$ rearranged irradiated patients with the nine $M Y C$ rearranged non-irradiated patients did not show 
a

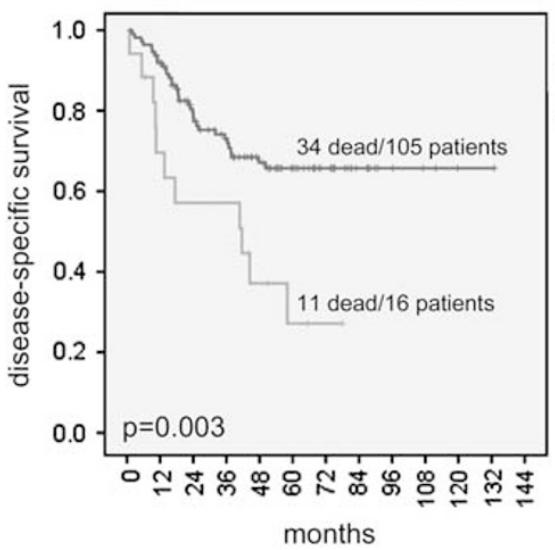

c
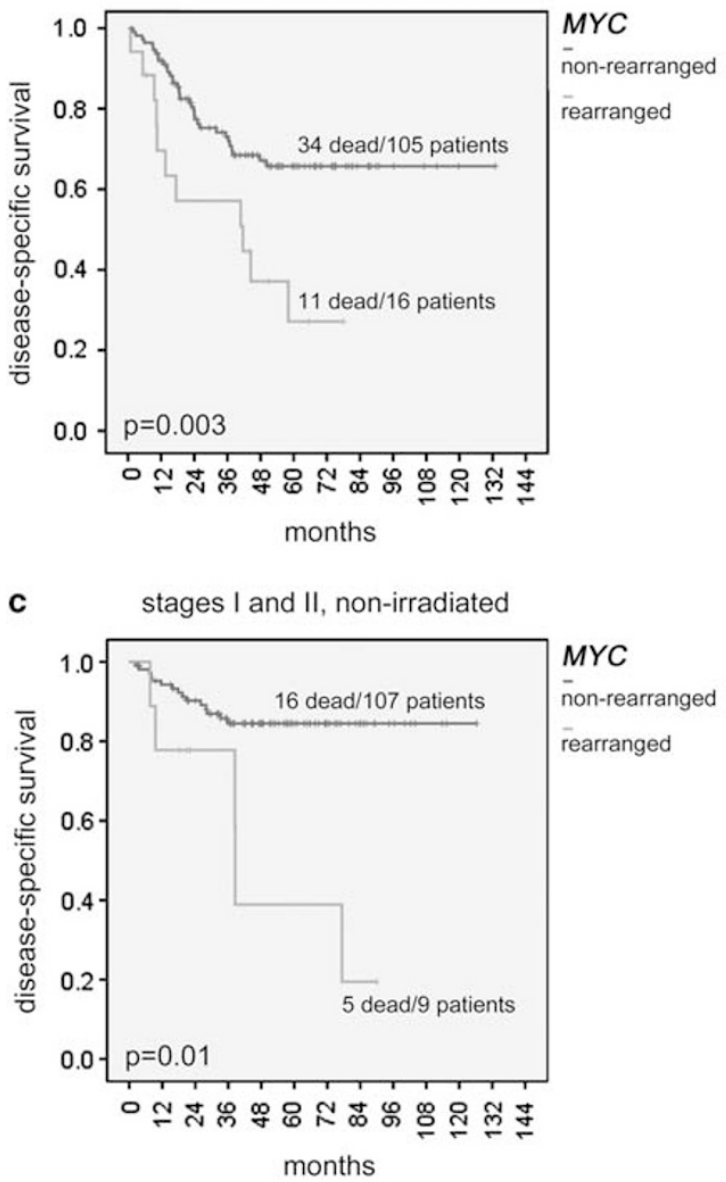

rearranged b

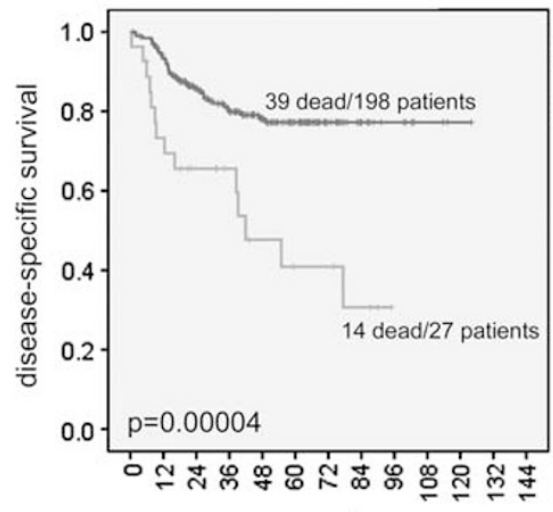

months

d

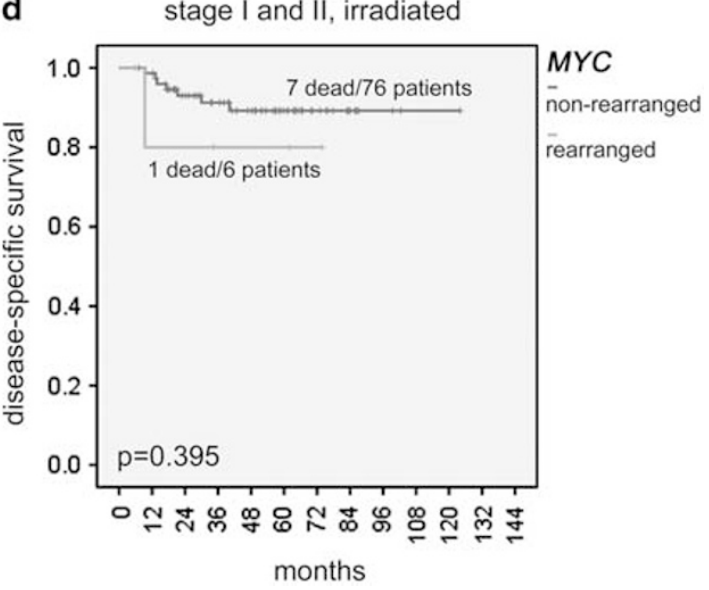

Figure 3 Kaplan-Meier survival curves comparing MYC rearranged and non-rearranged cases. (a) Survival estimates in phenotypic double-hit cases according to presence or absence of structural MYC hits. (b) Survival estimates according to presence or absence of structural MYC hits in germinal center B-cell cases. (c) Survival estimates according to presence or absence of structural MYC hits in irradiated and (d) non-irradiated stages I and II disease patients.

Table 4 Comparison of patients with stages I-II MYC rearranged diffuse large B-cell lymphomas stratified by radiation status; except for differences in gender distribution $(P=0.041)$, the distribution differences of all other variables did not reach statistical difference

Variable $^{\mathrm{a}}$

$\mathrm{N}$

Age, years

Gender (male: female)

B-symptoms

Bulk $(>10 \mathrm{~cm})$

Mean International Prognostic Index

Nodal: extranodal primary

R-CHOP-like regimens

Complete remission

Germinal center B-cell like

MYC protein, mean \%

Ki-67, mean \%

Bcl2, mean \%

BCL2 breaks
Irradiated Non-irradiated

$\begin{array}{cc}6 & 9 \\ 63 \pm 10 & 60 \pm 17 \\ 1: 5 & 7: 2 \\ 1 / 6 & 1 / 9 \\ 1 / 5 & 1 / 5 \\ 1.40 & 1.75 \\ 1: 5 & 3: 6 \\ 0 / 6 & 2 / 9 \\ 6 / 6 & 5 / 9 \\ 2 / 6 & 7 / 9 \\ 60 \pm 26 & 68 \pm 27 \\ 64 \pm 23 & 71 \pm 21 \\ 68 \pm 38 & 51 \pm 41 \\ 1 / 5 & 2 / 7\end{array}$

${ }^{\mathrm{a}}$ Data represent absolute numbers, ratios, or means. statistical significance $(P=0.233)$, probably due to low number cases; yet the survival curves implied a survival advantage for the former. Importantly, the distribution of patients who were given $<6$ cycles of R-CHOP (thus, considered potentially undertreated) among irradiated (3 of 6) and non-irradiated (1 of 9) MYC rearranged diffuse large B-cell lymphomas could not explain the observed more favorable outcome of the irradiated $M Y C$ rearranged patients.

The multivariable model results including all relevant factors from the univariable analyses are shown in Table 5.

\section{Differential Gene Expression between MYC Rearranged and Non-Rearranged Diffuse Large B-Cell Lymphomas}

To identify additional molecular mechanisms underlying the unfavorable outcome of patients 
Table 5 Multivariable analysis

\begin{tabular}{|c|c|c|c|c|c|c|}
\hline \multirow{2}{*}{ Variable } & \multicolumn{2}{|c|}{ Overall survival } & \multicolumn{2}{|c|}{ Disease-specific survival } & \multicolumn{2}{|c|}{ Progression-free survival } \\
\hline & $\mathrm{P}$-value & $\begin{array}{c}\text { Relative risk } \\
\text { (95\% confidence } \\
\text { interval) }\end{array}$ & $\mathrm{P}$-value & $\begin{array}{c}\text { Relative risk } \\
\text { (95\% confidence } \\
\text { interval) }\end{array}$ & $\mathrm{P}$-value & $\begin{array}{c}\text { Relative risk } \\
\text { (95\% confidence } \\
\text { interval) }\end{array}$ \\
\hline International Prognostic Index & $4.6 \mathrm{e} 5$ & $1.55(1.26-1.92)$ & $3.9 \mathrm{e} 5$ & $1.71(1.33-2.21)$ & $2.8 \mathrm{e} 4$ & $1.47(1.19-1.81)$ \\
\hline Bulky tumor & NS & & NS & & NS & \\
\hline B-symptoms & NS & & NS & & NS & \\
\hline R-CHOP-like treatment & 0.054 & $1.74(0.99-3.05)$ & 0.039 & $2.03(1.04-3.96)$ & 0.052 & $1.74(0.99-3.06)$ \\
\hline Cell of origin & $\begin{array}{l}\text { NS } \\
\text { NS }\end{array}$ & & $\begin{array}{l}\text { NS } \\
\text { NS }\end{array}$ & & $\begin{array}{l}\text { NS } \\
\text { NS }\end{array}$ & \\
\hline MYC protein expression & & & & & & \\
\hline MYC rearrangements & NS & & NS & & NS & \\
\hline$M C^{+} / \mathrm{MYC}^{-}$protein $^{+}$ & 0.091 & $1.83(0.91-3.82)$ & 0.046 & $2.16(1.01-4.61)$ & 0.098 & $1.76(0.88-3.53)$ \\
\hline Bcl2 protein expression & NS & & NS & & NS & \\
\hline Phenotypic double-hit & NS & & NS & & NS & \\
\hline Genetic double-hit & NS & & NS & & NS & \\
\hline
\end{tabular}

Abbreviation: NS, not significant.

with MYC rearranged diffuse large B-cell lymphomas, we compared the gene expression signatures of $M Y C$ rearranged and non-rearranged cases. $M Y C$ encodes for a transcription factor with both activating and repressing functions, which is thought to control approximately $10 \%$ of all human genes, ${ }^{35}$ promoting cell proliferation, cell growth, and biosynthesis as well as modulating apoptosis. ${ }^{17}$ Thus, it was not unexpected that, along with $M Y C$ itself, genes involved in intracellular biosynthesis such as TIMM8A, RIMKLB, RPL37, FBL, GTF2I, PSPH, DDX54, SMAD1, and CYCLIN B1 were upregulated in $M Y C$ rearranged cases (Figure 1d). Importantly, PEG10, the overexpression of which accompanies high-risk B-cell chronic lymphocytic leukemia, ${ }^{36}$ the transcriptional repressor or activator of $\mathrm{B}$ cells $B A C H 2$, the AKT, and NF- $\kappa \mathrm{B}$ coactivator TCL1A, as well as KCNQ5 (potassium voltage-gated channel, KQT-like subfamily, member 5) were also overexpressed. On the other hand, multiple genes involved in T-cell functions, particularly Th17-cellmediated functions such as IL17RB, BATF, CD58, $E B I 3$, and TRAF1 were downregulated in $M Y C$ rearranged cases. When analyzed in the different cell of origin subgroups, the MYC signature obtained from the whole cohort was retained in the germinal center B-cell cases, but not in the $12 \mathrm{MYC}$ rearranged activated B-cell cases, which were characterized by overexpression and downregulation of other genes (data not shown).

\section{Discussion}

We report a large-scale analysis of the prognostic significance of $M Y C$ aberrations in diffuse large B-cell lymphoma patients treated with R-CHOP. The strengths of our study, which considerably expands on previous knowledge, include the following: (i) homogenous cohort from the rituximab treatment era. (ii) Inclusion of treatment-naive, primary diffuse large B-cell lymphoma from human immunodeficiency virus-negative individuals. (iii) Exclusion of primary mediastinal large B-cell, primary cutaneous, and primary central nervous system large B-cell lymphomas. (iv) Collection of cases from multiple international centers. (v) Application of multiple FISH probes for the $M Y C$ gene. (vi) Complete histopathological and molecular documentation of cases allowing consideration of morphotypic, phenotypic, structural genetic (BCL2 and BCL6 gene status), and gene expression characteristics. (vii) Centralized evaluation of FISH by application of strict criteria for cutoff definition and assessment of both structural and numerical gene aberrations.

We identified structural aberrations of MYC in 9\% and amplifications in $<1 \%$ of cases. The most common structural aberration, observed in $51 \%$ of cases with aberrations, was the classical IGH/MYC fusion corresponding to $\mathrm{t}(8 ; 14)$, followed by $M Y C$ rearrangements with non-IGH partner genes (38\%) and t(8;14) with $M Y C$ breaks > 100-bp $5^{\prime}$ to the first gene exon (11\%), which are typical for endemic Burkitt lymphomas; $26 \%$ of $M Y C$ rearranged diffuse large B-cell lymphomas had prognostically relevant genetic double-hits involving the BCL2 gene. MYC rearrangements were predominantly encountered in germinal center B-cell cases (69\%), which was also reflected by their more common and abundant positivity for CD10. MYC rearrangements could not be predicted by any of the clinicopathological variables studied and could not be accurately predicted by MYC protein expression analysis (sensitivity $91 \%$ and specificity $36 \%$ ). Yet, patients whose diffuse large B-cell lymphomas had $M Y C$ rearrangements tended to present with larger masses or bulky tumors, more commonly and abundantly expressed MYC protein, and frequently (44\%) failed to achieve complete remission after R-CHOP treatment. $M Y C$ rearranged patients showed worse clinical outcome with respect to overall survival, disease-specific survival, and progression-free 
survival in all diffuse large B-cell lymphoma subgroups, defined by bulky disease, B-symptoms, and International Prognostic Index (except for highintermediate scores), phenotypic double-hit score, regardless of treatment with R-CHOP or R-CHOPlike regimens as well as in patients, whose lymphomas expressed Bcl2 in $<70 \%$ of tumor cells. Considering disease-specific survival, the prognostic impact of MYC rearrangement also applied to patients, whose lymphomas expressed Bcl 2 in $\geq 70 \%$ of cells. Still, further consideration of MYC protein expression in the context of the known $M Y C$ gene status had a considerable additive prognostic impact. This indicates that protein expression studies, although unable to reliably identify $M Y C$ rearranged diffuse large B-cell lymphomas, can help triage cases for and enhance the yield of FISH testing. Most importantly, a combined approach identifying structural aberrations of the MYC gene (FISH) and MYC protein overexpression (immunohistochemistry) seems promising, as in our cohort this 'double approach' was able to identify diffuse large B-cell lymphomas with worse disease-specific survival independent of the International Prognostic Index.

Our observed relative frequency of $9 \%$ structural MYC aberrations among unselected diffuse large B-cell lymphoma cases is in line with published series $^{8-11,13,20}$ being more commonly detectable, as reported, in cases expressing CD10 and the germinal center B-cell subtype. Previous studies reported lower frequencies of $M Y C$ aberrations in diffuse large B-cell lymphomas, ${ }^{12,37,38}$ but these studies were influenced by selection of cases with high tumor cell numbers, ${ }^{38}$ exclusion of highly proliferating, monomorphic-centrocytic, and ileocecal cases ${ }^{12}$ or were skewed toward younger individuals (median age 56 years) and women. ${ }^{37}$ Still, other studies reported higher frequencies of $M Y C$ rearrangements, ${ }^{39-41}$ but they were influenced by skewing toward older patients (median age 71 years), inclusion of only nodal and relapsed diffuse large B-cell lymphomas or by application of lower cutoff scores for FISH. With regard to the latter, application of low FISH scores does not reflect tumor biology and should be discouraged. ${ }^{42}$ Thus, the relative frequency of structural $M Y C$ aberrations in unselected diffuse large B-cell lymphomas can be assumed to be $8-10 \%$. Considering the reliable detection and interpretation of such cases, several debatable issues currently remain: (i) Is there a reliable surrogate for FISH? (ii) Which set of FISH probes should be applied? (iii) What kind of prognostic information is provided by the $M Y C$ rearrangement status? Our current data and analysis of previous reports ${ }^{18,43,44}$ suggest that although assessment of MYC protein might indicate the presence of $M Y C$ rearrangements and is, independent of the $M Y C$ gene status, a negative prognostic factor, ${ }^{18}$ its specificity and positive predictive value might not be reliable enough to substitute for assessment of MYC gene status. This is primarily due to multiple mechanisms regulating MYC, such as miR- $34^{45,46}$ or PTEN. ${ }^{47}$ Moreover, assessment of proliferation $^{12}$ and other clinicopathological parameters are not reliable identifiers of $M Y C$ rearranged diffuse large B-cell lymphomas. Nevertheless, a combined FISH and MYC protein detection approach seems to be worth further testing, as the negative prognostic impact of $M Y C$ rearrangements was limited to cases expressing MYC protein in at least $50 \%$ (>median) of tumor cells and identified patients at risk with respect to disease-specific survival in an International Prognostic Index-independent manner. Thus, although FISH remains the gold standard to identify structural MYC gene aberrations, a two-step approach starting with protein expression assessment followed by FISH examination in all cases with MYC protein expression over the cutoff score seems rational. Comparing the phenotypic and genotypic double-hit scoring system and the combined 'MYC immunohistochemistry/MYC FISH' two-step approach, the results of our multivariable analysis clearly favor the latter. Considering the design of FISH probes, break-apart probes identify a higher number of cases, as they also cover the prognostically relevant $M Y C$ rearrangements with non$I G H$ partners, although they are unable to identify a minor proportion (1\% of all diffuse large B-cell lymphomas, $11 \%$ of diffuse large B-cell lymphomas with structural $M Y C$ aberrations) of cases with $\mathrm{t}(8 ; 14)$ and $M Y C$ breaks $>100$-bp $5^{\prime}$ to the first exon. ${ }^{33,34}$ Such instances may warrant successive applications of break-apart probes and dual-fusion probes.

Our study provides the rationale to identify $M Y C$ rearrangements in diffuse large B-cell lymphomas with potential clinical applications. First, presence of MYC rearrangements detect diffuse large B-cell lymphoma cases likely to have a poor outcome and poor response to current treatment (R-CHOP). Even within the sub-cohort of phenotypic doublehit diffuse large B-cell lymphoma patients, presence of $M Y C$ rearrangements was associated with more unfavorable outcomes, improving the accuracy of the former method to identify patients at risk. Our findings also point to the need for prospective clinical trials to determine optimal strategies to overcome the $M Y C$-related treatment resistance, for example, application of DA-EPOCH-R ${ }^{48}$ and randomized study of the possible role of radiotherapy in limited stage disease, as suggested by our data. Detection of MYC rearrangements is also helpful in selecting diffuse large B-cell lymphoma patients in whom additional genetic testing for, at least, BCL2 is needed to identify so-called genetic double-hit lymphomas, ${ }^{16}$ which represent a true oncological challenge and are clearly under-treated by R-CHOP. Finally, as suggested by the specific gene expression profiles of $M Y C$ rearranged diffuse large B-cell lymphomas, these cases might harbor specific targetable molecules and pathways. At least two potential targets identified in our study are: (i) overexpression of the potassium voltage-gated channel, KQT-like 
subfamily, member 5, KCNQ1 and (ii) Suppression of multiple genes involved in Th17-mediated functions. There is growing evidence that potassium channels have an important role in oncogenesis, and their potential as therapeutic targets in cancer has been recognized recently. ${ }^{49}$ Thus, the identification of $K C N Q 5$, specifically blockable by linopiridine, ${ }^{50}$ as upregulated in $M Y C$ rearranged diffuse large B-cell lymphomas seems a promising therapeutic approach. Whether the suppression of genes mediating T-cell functions, particularly Th17-cell functions, reflects a specific tumor cell/T-cell interaction in $M Y C$ rearranged diffuse large B-cell lymphomas related to MYC protein activity, indicates other complex immunologic interactions or mirrors a numerical change of tumor-infiltrating $\mathrm{T}$ cells, needs to be further clarified, as this finding may represent a potential target for immunomodulatory derivatives.

We acknowledge potential weaknesses of our study. This study is retrospective in nature with missing clinical data in some patients. A subset of patients in this study, 15\%, received R-CHOP-like regimens instead of R-CHOP regimens. However, $M Y C$ rearrangements were connoted poor prognostic significance in both patients treated with R-CHOP and those treated with R-CHOP-like regimens. Application of R-CHOP-like regimens had a major impact on overall survival only, implying that mainly patient-related factors such as age and comorbidity, which required modification in anthracycline usage, and not tumor-related factors might largely be responsible for the poorer outcome of individuals treated with R-CHOP-like regimens.

In summary, $M Y C$ rearrangements can be detected in $9 \%$ of diffuse large B-cell lymphomas; $5 \%$ are detectable by both, break-apart probes and dualfusion probes, $3 \%$ by break-apart probes and $1 \%$ by dual-fusion probes only. Patients with $M Y C$ rearranged diffuse large B-cell lymphomas more frequently present with bulky disease, fail to achieve complete remission with R-CHOP therapy and have poorer disease-specific survival, independent of the International Prognostic Index, if their tumors express MYC protein in more than half of the tumor cells. Even within phenotypic double-hit diffuse large B-cell lymphoma cases, presence of $M Y C$ rearrangements is associated with more unfavorable outcomes, improving the accuracy of the former method to identify higher risk patients. In all, 70\% of $M Y C$ rearranged diffuse large B-cell lymphomas are of the germinal center B-cell origin and one-third have a second, prognostically deleterious, BCL2 hit. Adjuvant radiotherapy might have possible potential to influence the outcome especially in limited stage $M Y C$ rearranged diffuse large B-cell lymphoma patients. However, this point needs clarification in prospective trials. Finally, a potentially targetable potassium voltage-gated channel, KCNQ5, is specifically overexpressed in $M Y C$ rearranged diffuse large B-cell lymphomas, a finding that warrants further investigation.

\section{Acknowledgments}

This work was supported by the Zurich Stiftung zur Krebsbekaempfung grant 269 and Krebsliga Beider Basel (AT); the University of Texas MD Anderson Cancer Center Institutional R \& D Fund, an Institutional Research Grant Award, an MD Anderson Lymphoma SPORE Research Development Program Award (KHY). This work was also partially supported by National Cancer Institute and National Institute of Health (R01CA138688, 1RC1CA146299, P50CA136411, and P50CA142509, KHY), and by the MD Anderson Cancer Center Support Grant CA016672.

\section{Disclosure/conflict of interest}

The authors declare no conflicts of interest.

\section{References}

1 Stein H, Warnke RA, Chan WC, et al. Diffuse large B-cell lymphoma, not otherwise specified, In: Swerdlow SC, Campo E, Harris NL, et al. (eds) WHO Classification of Tumours of Haematopoietic and Lymphoid Tissues. IARC Press: Lyon, France; 2008, pp 233-237.

2 Chan WJ. Pathogenesis of diffuse large B cell lymphoma. Int J Hematol 2010;92:219-230.

3 Alizadeh AA, Eisen MB, Davis RE, et al. Distinct types of diffuse large B-cell lymphoma identified by gene expression profiling. Nature 2000;403:503-511.

4 Rosenwald A, Wright G, Chan WC, et al. The use of molecular profiling to predict survival after chemotherapy for diffuse large-B-cell lymphoma. N Engl J Med 2002;346:1937-1947.

5 Wright G, Tan B, Rosenwald A, et al. A gene expression-based method to diagnose clinically distinct subgroups of diffuse large B cell lymphoma. Proc Natl Acad Sci USA 2003;100:9991-9996.

$6 \mathrm{Fu} \mathrm{K}$, Weisenburger DD, Choi WW, et al. Addition of rituximab to standard chemotherapy improves the survival of both the germinal center B-cell-like and non-germinal center B-cell-like subtypes of diffuse large B-cell lymphoma. J Clin Oncol 2008;26: 4587-4594

7 Boerma EG, Siebert R, Kluin PM, et al. Translocations involving 8q24 in Burkitt lymphoma and other malignant lymphomas: a historical review of cytogenetics in the light of todays knowledge. Leukemia 2009;23: 225-234.

8 Kramer $\mathrm{MH}$, Hermans J, Wijburg E, et al. Clinical relevance of BCL2, BCL6, and MYC rearrangements in diffuse large B-cell lymphoma. Blood 1998;92: 3152-3162.

9 Savage KJ, Johnson NA, Ben-Neriah S, et al. MYC gene rearrangements are associated with a poor prognosis in diffuse large B-cell lymphoma patients treated with R-CHOP chemotherapy. Blood 2009;114:3533-3537.

10 Klapper W, Stoecklein H, Zeynalova S, et al. German High-Grade Non-Hodgkin's Lymphoma Study Group. Structural aberrations affecting the MYC locus indicate a poor prognosis independent of clinical risk factors in diffuse large B-cell lymphomas treated within rando- 
mized trials of the German High-Grade Non-Hodgkin's Lymphoma Study Group (DSHNHL). Leukemia 2008; 22:2226-2229.

11 Niitsu N, Okamoto M, Miura I, et al. Clinical features and prognosis of de novo diffuse large B-cell lymphoma with $\mathrm{t}(14 ; 18)$ and 8q24/c-MYC translocations. Leukemia 2009;23:777-783.

12 Obermann EC, Csato M, Dirnhofer S, et al. Aberrations of the MYC gene in unselected cases of diffuse large B-cell lymphoma are rare and unpredictable by morphological or immunohistochemical assessment. J Clin Pathol 2009;62:754-756.

13 Yoon SO, Jeon YK, Paik JH, et al. MYC translocation and an increased copy number predict poor prognosis in adult diffuse large B-cell lymphoma (DLBCL), especially in germinal centre-like B cell (GCB) type. Histopathology 2008;53:205-217.

14 Johnson NA, Savage KJ, Ludkovski O, et al. Lymphomas with concurrent BCL2 and MYC translocations: the critical factors associated with survival. Blood 2009;114:2273-2279.

15 Ueda C, Nishikori M, Kitawaki T, et al. Coexistent rearrangements of c-MYC, BCL2, and BCL6 genes in a diffuse large B-cell lymphoma. Int J Hematol 2004; 79:52-54.

16 Aukema SM, Siebert R, Schuuring E, et al. Double-hit B-cell lymphomas. Blood 2011;117:2319-2331.

17 Slack GW, Gascoyne RD. MYC and aggressive B-cell lymphomas. Adv Anat Pathol 2011;18:219-228.

18 Green TM, Young KH, Visco C, et al. Immunohistochemical double-hit score is a strong predictor of outcome in patients with diffuse large B-cell lymphoma treated with rituximab plus cyclophosphamide, doxorubicin, vincristine, and prednisone. J Clin Oncol 2012;30:3460-3467.

$19 \mathrm{Hu} \mathrm{S}$, Xu-Monette ZY, Tzankov A, et al. MYC/BCL2 protein co-expression associated with high-risk gene signatures contributes to the inferior prognosis of activated B-cell subtype of DLBCL. Blood 2013;121: 4021-4031.

20 Akyurek N, Uner A, Benekli M, et al. Prognostic significance of MYC, BCL2 and BCL6 rearrangements in patients with diffuse large B-cell lymphoma treated with cyclophosphamide, doxorubicin, vincristine, and prednisone plus rituximab. Cancer 2012;118: 4173-4183.

21 Johnson NA, Slack GW, Savage KJ, et al. Concurrent expression of MYC and BCL2 in diffuse large B-cell lymphoma treated with rituximab plus cyclophosphamide, doxorubicin, vincristine, and prednisone. J Clin Oncol 2012;30:3452-3459.

22 Cheson BD, Pfistner B, Juweid ME, et al. International Harmonization Project on Lymphoma. Revised response criteria for malignant lymphoma. J Clin Oncol 2007;25:579-586.

23 Obermann EC, Csato M, Dirnhofer S, et al. BCL2 gene aberration as an IPI-independent marker for poor outcome in non-germinal-centre diffuse large B cell lymphoma. J Clin Pathol 2009;62:903-907.

24 Tzankov A, Schneider A, Hoeller S, et al. Prognostic importance of BCL6 rearrangements in diffuse large B-cell lymphoma with respect to Bcl6 protein levels and primary lymphoma site. Hum Pathol 2009;40: 1055-1056.

25 Tzankov A, Zlobec I, Went $\mathrm{P}$, et al. Prognostic immunophenotypic biomarker studies in diffuse large B cell lymphoma with special emphasis on rational determination of cut-off scores. Leuk Lymphoma 2010; 51:199-212.

26 Visco C, Tzankov A, Xu-Monette ZY, et al. BCL2 rearrangement characterizes a subset of patients with diffuse large B cell lymphoma of germinal center origin with poor outcome: a report from an international DLBCL rituximab-CHOP consortium program study. Haematologica 2013;98:255-263.

27 Visco C, Li Y, Xu-Monette ZY, et al. Comprehensive gene expression profiling and immunohistochemical studies support application of immunophenotypic algorithm for molecular subtype classification in diffuse large B-cell lymphoma: a report from the International DLBCL Rituximab-CHOP Consortium Program Study. Leukemia 2012;26:2103-2113.

28 McShane LM, Altman DG, Sauerbrei W, et al. Statistics Subcommittee of the NCI-EORTC Working Group on Cancer Diagnostics. REporting recommendations for tumour MARKer prognostic studies (REMARK). Eur J Cancer 2005;41:1690-1696.

29 Pfreundschuh $\mathrm{M}$, Ho AD, Cavallin-Stahl E, et al. MabThera International Trial (MInT) Group. Prognostic significance of maximum tumour (bulk) diameter in young patients with good-prognosis diffuse large-Bcell lymphoma treated with CHOP-like chemotherapy with or without rituximab: an exploratory analysis of the MabThera International Trial Group (MInT) study. Lancet Oncol 2008;9:435-444.

30 Bertrand P, Bastard C, Maingonnat C, et al. Mapping of MYC breakpoints in 8q24 rearrangements involving non-immunoglobulin partners in B-cell lymphomas. Leukemia 2007;21:515-523.

31 Bertrand P, Maingonnat C, Picquenot JM, et al. Characterization of three $\mathrm{t}(3 ; 8)(\mathrm{q} 27 ; \mathrm{q} 24)$ translocations from diffuse large B-cell lymphomas. Leukemia 2008;22: 1064-1067.

32 Wang HY, Bossler AD, Schaffer A, et al. A novel t(3;8) (q27;q24.1) simultaneously involving both the BCL6 and MYC genes in a diffuse large B-cell lymphoma. Cancer Genet Cytogenet 2007;172:45-53.

33 Shiramizu B, Barriga F, Neequaye J, et al. Patterns of chromosomal breakpoint locations in Burkitt's lymphoma: relevance to geography and Epstein-Barr virus association. Blood 1991;77:1516-1526.

34 Pelicci PG, Knowles DM 2nd, Magrath I, et al. Chromosomal breakpoints and structural alterations of the c-myc locus differ in endemic and sporadic forms of Burkitt lymphoma. Proc Natl Acad Sci USA 1986;83:2984-2988.

35 Fernandez PC, Frank SR, Wang L, et al. Genomic targets of the human c-Myc protein. Genes Dev 2003;17:1115-1129.

36 Kainz B, Shehata M, Bilban M, et al. Overexpression of the paternally expressed gene 10 (PEG10) from the imprinted locus on chromosome 7q21 in high-risk B-cell chronic lymphocytic leukemia. Int J Cancer 2007;121:1984-1993.

37 Akyurek N, Uner A, Benekli M, et al. Prognostic significance of MYC, BCL2, and BCL6 rearrangements in patients with diffuse large B-cell lymphoma treated with cyclophosphamide, doxorubicin, vincristine, and prednisone plus rituximab. Cancer 2012;118: 4173-4183.

38 Copie-Bergman C, Gaulard P, Leroy K, et al. Immunofluorescence in situ hybridization index predicts survival in patients with diffuse large B-cell lymphoma treated with R-CHOP: a GELA study. J Clin Oncol 2009;27:5573-5579. 
39 Barrans S, Crouch S, Smith A, et al. Rearrangement of MYC is associated with poor prognosis in patients with diffuse large B-cell lymphoma treated in the era of rituximab. J Clin Oncol 2010;28:3360-3365.

40 Cuccuini W, Briere J, Mounier N, et al. MYC + diffuse large B-cell lymphoma is not salvaged by classical R-ICE or R-DHAP followed by BEAM plus autologous stem cell transplantation. Blood 2012;119:4619-4624.

41 Tibiletti MG, Martin V, Bernasconi B, et al. BCL2, BCL6, MYC, MALT 1, and BCL10 rearrangements in nodal diffuse large B-cell lymphomas: a multicenter evaluation of a new set of fluorescent in situ hybridization probes and correlation with clinical outcome. Hum Pathol 2009;40:645-652.

42 Haralambieva E, Kleiverda K, Mason DY, et al. Detection of three common translocation breakpoints in non-Hodgkin's lymphomas by fluorescence in situ hybridization on routine paraffin-embedded tissue sections. J Pathol 2002;198:163-170.

43 Tapia G, Lopez R, Muñoz-Mármol AM, et al. Immunohistochemical detection of MYC protein correlates with MYC gene status in aggressive B cell lymphomas. Histopathology 2011;59:672-678.

44 Kluk MJ, Chapuy B, Sinha P, et al. Immunohistochemical detection of MYC-driven diffuse large B-cell lymphomas. PLoS One 2012;7:1-9.
45 Leucci E, Cocco M, Onnis A, et al. MYC translocationnegative classical Burkitt lymphoma cases: an alternative pathogenetic mechanism involving miRNA deregulation. J Pathol 2008;216:440-450.

46 Craig VJ, Cogliatti SB, Imig J, et al. Myc-mediated repression of microRNA-34a promotes high-grade transformation of B-cell lymphoma by dysregulation of FoxP1. Blood 2011;117:6227-6236.

47 Bonnet M, Loosveld M, Montpellier B, et al. Posttranscriptional deregulation of MYC via PTEN constitutes a major alternative pathway of MYC activation in T-cell acute lymphoblastic leukemia. Blood 2011; 117:6650-6659.

48 Dunleavy K, Pittaluga S, Wayne S, et al. Myc + agressive B-cell lymphomas: novel therapy of untreated Burkitt lymphoma (BL) and $\mathrm{Myc}+$ diffuse large B-cell lymphoma (DLBCL) with DA-EPOCH-R. Ann Oncol 2011;22(Suppl 4):071.

49 D’Amico M, Gasparoli L, Arcangeli A. Potassium channels: novel emerging biomarkers and targets for therapy in cancer. Recent Pat Anticancer Drug Discov 2013;8:53-65.

50 Gutman GA, Chandy KG, Grissmer S, et al. International Union of Pharmacology. LIII. Nomenclature and molecular relationships of voltage-gated potassium channels. Pharmacol Rev 2005;57:473-508. 